\title{
Kleptomania: a case series
}

Bharat Saluja ${ }^{1}$, MD, Lai Gwen $\underline{\text { Chan }}^{2}$, MBBS, MRCPsych, Dani Dhaval ${ }^{3}$, MBBS

ABSTRACT Kleptomania is an enigmatic condition and is among the very few psychiatric disorders in which crime is medicalised and used as a legal defence. The scientific literature on kleptomania is scarce. Early literature and recent studies have shown a female preponderance, with an early age of onset of stealing in people with comorbid personality disorder(s). In a retrospective review of the case notes of theft offenders who had forensic psychiatric evaluations performed in a one-year period in 2010 at the Institute of Mental Health, Singapore, we found three patients who were diagnosed with kleptomania. In this report, we describe the pertinent clinical and sociodemographic characteristics, as well as the diagnostic issues of kleptomania in relation to the three cases.

Keywords: case series, diagnostic issues, kleptomania, shoplifters

\section{INTRODUCTION}

Kleptomania is an enigmatic condition in which crime (theft) forms a part of its diagnostic criteria. Not surprisingly, it is commonly used by the defence counsel for mitigation of theft and related offences, especially for repeat theft offenders.

Kleptomania is described in both the medical and legal literatures for centuries, dating back to the early 19th century when the Swiss physician Mathey who worked with the "insane" wrote of "a unique madness characterised by the tendency to steal without motive and without necessity. The tendency to steal is permanent [...] but the thieving tendency triumphs, it subjugates the will."(1) He termed this condition as 'klopemania' or a 'stealing insanity'. The term 'klopemania' changed to 'kleptomanie' and described by the French physicians Marc and Esquirol as "persons having irresistible and involuntary urges to steal."(1) Subsequently, kleptomania was included in the Diagnostic and Statistical Manual of Mental Disorders (DSM-I) in 1962 as a supplementary term rather than a formal diagnosis. Interestingly, the term was omitted altogether from the DSM-II before being reintroduced in the DSM-III under the category of 'impulse control disorder not otherwise specified'. Kleptomania retains its position under the same diagnostic category in DSM-IV-TR. ${ }^{(2)}$ The DSM-IV-TR diagnostic criteria for kleptomania are listed in Table I.

It is easy to mis- or overdiagnose kleptomania because the majority of the condition's diagnostic criteria (recurrent failure to resist impulses to steal; increasing sense of tension immediately before committing the theft; and pleasure, gratification, or relief at the time of committing the theft) are based on self-reporting and it is difficult to test its reliability. As far as the diagnostic criterion that 'the stealing is not committed to express anger or vengeance' goes, an assessor may need several sessions to understand the motive(s) for the individual's behaviour(s). Patients are usually secretive and may not be consciously aware of their motive at the time of their assessments. The final criterion for kleptomania requires clinicians to exclude that 'stealing is not better accounted for by conduct disorder, a manic episode, or antisocial personality

\section{Table I. The diagnostic criteria for kleptomania. ${ }^{(2)}$}

- Recurrent failure to resist impulses to steal objects that are not
needed for personal use or for their monetary value
- Increasing sense of tension immediately before committing the
theft
- Pleasure, gratification, or relief at the time of committing the theft
- The stealing is not committed to express anger or vengeance
and is not in response to a delusion or a hallucination
- The stealing is not better accounted for by conduct disorder, a
manic episode, or antisocial personality disorder

disorder'. Interestingly, the diagnostic criteria of kleptomania does not require the exclusion of depressive disorder and personality disorders (barring antisocial personality disorder) as the likely cause of stealing behaviours.

The existing literature indicates that kleptomaniacs often report lack of self-esteem, a difficult childhood and marital conflicts, ${ }^{(3)}$ which may just be one of the manifestations of borderline personality disorder, ${ }^{(4,5)}$ and score poorly on socialisation but well on impulsivity and novelty seeking. ${ }^{(6,7)}$

Kleptomaniacs have high rates of substance abuse and mood disorders, ${ }^{(8)}$ as well as anxiety disorders. ${ }^{(9)}$ The extent to which obsessive compulsive disorder (OCD) and kleptomania co-occur is not well understood. Rates of co-occurring OCD in samples of kleptomaniacs have ranged from $6.5 \%{ }^{(9)}$ to $60 \% .{ }^{(10)} \mathrm{A}$ recent study ${ }^{(11)}$ reported that kleptomaniacs who seek treatment have a higher prevalence of personality disorders compared to a nonclinical population.

Early literature suggested that kleptomania particularly affected women of high social and economic status so much so that scientists assumed its aetiology as stemming from the female reproductive system. It is not that scientists did not describe cases of male and lower class kleptomaniacs in the 19th century, but the evidence made no headway as the media was more interested in socially prominent women thieves who used kleptomania as a defence in court trials. Newer studies have also shown a female

${ }^{1}$ Department of General and Forensic Psychiatry, Institute of Mental Health, ${ }^{2}$ Department of Psychological Medicine, Tan Tock Seng Hospital, ${ }^{3}$ Department of General and Forensic Psychiatry, Institute of Mental Health, Singapore

Correspondence: Dr Bharat Saluja, Consultant, Department of General and Forensic Psychiatry, Institute of Mental Health, 10 Buangkok View, Singapore 539747. drbharatsaluja@gmail.com 
preponderance, ${ }^{(12,13)}$ with an early age of onset of stealing in females $^{(10)}$ and people with comorbid personality disorders. ${ }^{(14,15)}$

To summarise, kleptomania is difficult to diagnose and clinicians should exhibit a high degree of caution in diagnosing it in view of its legal implications. We herein describe the sociodemographic, pertinent clinical characteristics and diagnostic issues of three patients who received a past or present diagnosis of kleptomania. These patients were identified in the course of conducting a retrospective review of theft offenders at the Institute of Mental Health, Singapore, for the year 2010.

\section{CASE REPORTS}

\section{Case 1}

A 45-year-old, divorced Chinese male was remanded three times in the same year for the same charges and evaluated specifically with regard to kleptomania. He had attained the GCE 'A' Level qualifications and was unemployed. He had previously been diagnosed with conduct disorder, alcohol dependence, depression, and antisocial personality disorder. He had started shoplifting from the age of 29. The diagnosis of kleptomania had been considered a few times but not established because of the lack of corroboration of his self-reported history of kleptomaniac pattern of stealing and the presence of other diagnoses that are assumed to preclude kleptomania according to the criteria. What further complicated the diagnostic issue was that he was likely to have been intoxicated by alcohol at the material time. He gave a history of stealing for fun together with friends during his teenage years. He started stealing again in his late twenties, committing the act more times than he was caught, but had spent more than seven years in prison for shoplifting items that he had no personal use for. The stolen items included candles, crayons, children's scissors, irons, bottles of ink, coloured papers, printers, earrings, brooches, batteries, and shavers, and he kept these items in a cupboard at home. However, the house had been sold after his divorce, and his ex-wife could only corroborate seeing many electronic and stationery items that were never used and said that he claimed they had been given to him by people who owed him money. He also reported that he only stole on impulse and not from premeditation; he experienced tension prior to, and satisfaction after, shoplifting. In order to substantiate his history, details of his past criminal records of theft were requested from the Investigating Officer in charge of his case, and they were fairly consistent with what he reported. This case is interesting in that even though he had been diagnosed with conduct disorder and antisocial personality disorder, there was no evidence that these conditions accounted for all his acts of stealing, and that there were distinctly different patterns of stealing at different points in his life. He was finally diagnosed with antisocial personality disorder, alcohol dependence and kleptomania, and it was concluded that kleptomania contributed to only some of his offences.

\section{Case 2}

A 46-year-old, married Chinese male, who had attained the GCE 'A' Level qualifications and worked part-time, started stealing in his late twenties and had several convictions for theft. He had also been previously diagnosed with OCD (repeated checking and washing secondary to obsessions of pathological doubt and contamination) and kleptomania. His index offence included stealing several cash cards at different points of time. He stated that he had a sudden urge to steal cash cards upon noticing unlocked cars, accompanied by heightened anxiety and then getting a sense of satisfaction and gratification after the completion of theft. None of the acts were premeditated. He stated that he would feel ashamed of himself after his acts and would place the cash card(s) either in a box or a card holder at home. His family members confirmed that they had found a box and card holder containing more than 100 cash cards. Out of several stolen cash cards, he had credited the cash value of one card into his bank account. Stealing items for their monetary value excludes the diagnosis of kleptomania; this case highlights the point that kleptomaniacs can have acts of stealing that are not accounted for by the laid diagnostic criteria. It also indicates a complex relationship between impulse control disorders and OCD, heterogeneity within the impulse control disorders, and a complicated overlap between impulsivity and compulsivity.

\section{Case 3}

A 60-year-old, divorced Indian woman who had completed Primary 6 education and had various manual jobs, started shoplifting from the age of 30 . She had multiple convictions of theft and several remand admissions. She was diagnosed with recurrent depression. She reported acts of stealing both during and outside her depressive episodes. The acts of stealing were typically due to failure to resist the tension and strong urge to take the items without paying, and feeling satisfied after taking them. The items typically were of no use to her. She stated that the acts of shoplifting helped to lift her mood temporarily during the depressive episodes. However, she would later feel guilty, which subsided when she either threw away or gave the items to others. Regarding her shoplifting behaviours when she was not suffering from depressive episodes, she stated she could recognise that her mood would be marginally low during those times but she was still able to function normally. The diagnostic criteria for kleptomania do not exclude depressive disorders as a contributory factor for the diagnosis of kleptomania. This case illustrates that depressive disorder is closely linked to kleptomania and makes us think whether kleptomania may represent another form of affective spectrum disorder.

\section{DISCUSSION}

The three reported cases highlight the pertinent clinical and sociodemographic characteristics, and diagnostic issues of individuals with kleptomania. The three patients (one female, 2 males), of Chinese and Indian ethnicities and aged between 45 and 60 years, demonstrated early age of onset of theft (i.e. early twenties). Barring the female patient, the attained education level of the case patients was GCE 'A' Level qualifications. They were all once married.

The individuals were convicted on multiple occasions for theft, and were remanded several times. The stolen items were of 
no personal use, and Patients 1 and 2 even revealed that their acts of stealing were not premeditated. Rather, they all experienced an urge and tension or anxiety prior to the act of stealing, followed by the feeling of satisfaction and gratification after committing theft. Patients 2 and 3 stated that they felt ashamed or guilty after committing theft.

These cases help to highlight the issues of diagnosing kleptomania in relation to the individual's concurrent disorders. Patient 1 was previously diagnosed with conduct disorder, alcohol dependence, depression, and antisocial personality disorder. His case highlighted that although conduct disorder and antisocial personality disorder were diagnosed, there was no evidence to suggest that these disorders accounted for all his committed thefts, because there were distinctly different patterns in his acts of stealing. Patient 2, who was diagnosed with OCD, is an example of individuals with kleptomania who can commit theft that is not accounted for by the laid diagnostic criteria for kleptomania, further revealing the complicated diagnostic issues. Similarly, Patient 3, who suffered from recurrent depression, demonstrates that the diagnostic criteria for kleptomania do not exclude depressive disorders as a contributory factor for the diagnosis of kleptomania; depressive disorder is closely associated with kleptomania, thereby suggesting that kleptomania may represent another form of affective spectrum disorder.

To conclude, our report described patients with diagnoses of kleptomania, all of whom had at least one concurrent disorder, including conduct disorder, antisocial personality disorder, alcohol dependence, OCD and depressive disorder. The cases illustrate details in the patients' histories that are required to satisfy each criterion in the diagnosis of kleptomania, and demonstrate some diagnostic pitfalls that clinicians must be cautious of. Individuals diagnosed with kleptomania typically have a long history of multiple acts of stealing and multiple convictions. This warrants a very careful and thorough evaluation of each and every act, as such individuals can also commit acts of theft that are not kleptomaniac in nature, but related to their comorbidities, need, or greed. The presence of concurrent disorders has to be assessed and its relationship with each offence elucidated.

\section{REFERENCES}

1. Ronald AF, Girish NP. Kleptomania: A brief intellectual history. Association for Historical Research in Marketing 2003; 201-209.

2. American Psychiatric Association. Diagnostic and Statistical Manual of Mental Disorders, Fourth Edition: DSM-IV-TR. American Psychiatric Pub, 2000.

3. Goldman MJ. Kleptomania: The Compulstion to Steal - What Can Be Done. Far Hills, NJ: New Horizon Press, 1998.

4. McElroy SL, Hudson JI, Pope HG, Keck PE. Kleptomania: clinical characteristics and associated psychopathology. Psychol Med 1991; 21:93-108.

5. Grant JE, Kim SW. Clinical characteristics and associated psychopathology of 22 patients with kleptomania. Compr Psychiatry 2002; 43:378-84.

6. Grant JE, Kim SW. Temperament and early environmental influences in kleptomania. Compr Psychiatry 2002; 43:223-8.

7. Sarasalo E, Bergman B, Toth J. Personality traits and psychiatric and somatic morbidity among kleptomaniacs. Acta Psychiatr Scand 1996; 94:358-64.

8. Baylé FJ, Caci H, Millet B, Richa S, Olié JP. Psychopathology and comorbidity of psychiatric disorders in patients with kleptomania. Am J Psychiatry 2003; 160:1509-13

9. Grant JE. Family history and psychiatric comorbidity in persons with kleptomania. Compr Psychiatry 2003; 44:437-41.

10. Presta S, Marazziti D, Dell'Osso L, et al. Kleptomania: clinical features and comorbidity in an Italian sample. Compr Psychiatry 2002; 43:7-12.

11. Grant JE. Co-occurrence of personality disorders in persons with kleptomania: a preliminary investigation. J Am Acad Psychiatry Law 2004; 32:395-8.

12. Aboujaoude E, Gamel N, Koran LM. Overview of Kleptomania and Phenomenological Description of 40 Patients. Prim Care Companion J Clin Psychiatry 2004; 6:244-7.

13. Sarasalo E, Bergman B, Toth J. Theft behaviour and its consequences among kleptomaniacs and shoplifters--a comparative study. Forensic Sci Int 1997; 86:193-205.

14. Grant JE, Potenza MN. Gender-related differences in individuals seeking treatment for kleptomania. CNS Spectr 2008; 13:235-45.

15. Hoertel N, Dubertret C, Schuster JP, Le Strat Y. Sex differences in shoplifting: results from a national sample. J Nerv Ment Dis 2012; 200:728-33. 